\title{
Familial Autoimmune Myasthenia Gravis: Four Patients Involving Three Generations
}

\author{
R.A. Marrie, D.J. Sahlas and G.M. Bray
}

\begin{abstract}
Background: Familial autoimmune myasthenia gravis (MG) is rare, although a genetic role for the development of autoimmune MG is suggested by concordance in monozygotic twins and the increased frequency of other autoimmune diseases in family members of myasthenics. Methods: A patient with a family history of MG was evaluated in hospital. Relatives were interviewed and medical records examined for details regarding the diagnosis of MG in three other family members. Results: The index case first experienced symptoms of $\mathrm{MG}$ at age 75 years. She developed generalized MG and required corticosteroids and immunosuppressive therapy to control her disease. Her father developed predominantly bulbar symptoms of MG at age 75 years. He died of complications experienced following a gastrostomy placed for continued difficulty swallowing. His brother developed similar symptoms of MG in his early 60s and died shortly after thymectomy. A 46-year-old nephew of the index case is also beginning to exhibit signs of generalized MG. Acetylcholine receptor antibodies were strongly positive in the index case and her nephew. (The assay was not available for her father and uncle). Conclusions: Four individuals in three successive generations had diagnoses of autoimmune MG. Study of familial cases such as these may clarify the contribution of genetic factors to the development of this disease.
\end{abstract}

\begin{abstract}
RÉSUMÉ:La myasthénie grave autoimmune familiale: quatre patients surtrois générations. Introduction: La myasthénie grave (MG) familiale autoimmune est rare, bien que la concordance chez les jumeaux monozygotes et la fréquence accrue d'autres maladies autoimmunes chez les membres de la famille des myasthéniques suggèrent que la génétique joue un rôle dans le développement de la MG autoimmune. Méthodes: Un patient ayant une histoire familiale de MG a été hospitalisé pour une évaluation. La parenté a été questionnée et les dossiers médicaux ont été examinés concernant le diagnostic de MG chez trois autres membres de la famille. Résultats: Le cas index a présenté les premiers symptômes de MG à 75 ans. Elle a développé une MG généralisée et a eu besoin de corticostéroïdes et d'un traitement immunosuppresseur pour contrôler sa maladie. Son père avait développé des symptômes d'une MG à prédominance bulbaire à l'âge de 75 ans. Il est décédé de complications suite à une gastrostomie pour pallier à la dysphagie. Son frère a développé des symptômes similaires au début de la soixantaine et est décédé peu après une thymectomie. Un neveu du cas index, âgé de 46 ans, commence à présenter des signes de MG généralisée. Les anticorps dirigés contre le récepteur de l'acétylcholine étaient fortement positifs chez le cas index et son neveu. (Le test n'était pas disponible pour le père et l'oncle). Conclusions: Quatre individus sur trois générations successives ont reçu un diagnostic de MG autoimmune. L'étude de cas familiaux comme ceux-ci peut aider à déterminer la contribution de facteurs génétiques dans le développement de cette maladie.
\end{abstract}

Can. J. Neurol. Sci. 2000; 27: 307-310

Myasthenia gravis (MG) results from impaired function of the acetylcholine receptor (AChR) at the neuromuscular junction. This can arise from inherited defects of the AChR, or from an autoimmune-mediated blockade of receptor sites. ${ }^{1}$ A genetic role for the development of autoimmune $\mathrm{MG}$ is suggested by concordance in monozygotic twins ${ }^{2}$ and by an increased frequency of other autoimmune diseases in myasthenics and their family members. ${ }^{3,4}$ Familial autoimmune MG has rarely been known to occur, with reported incidences ranging from 1.4 to $5.0 \% .^{5,6}$
Autoimmune MG has only once been reported to occur in three generations. ${ }^{6-8}$ Families with up to five affected family members have been described. ${ }^{9}$ We report a patient with

\footnotetext{
From the Division of Neurology, Montreal General Hospital, - McGill University Health Centre, Montréal, Québec, Canada.

ReCEIVED OCtOBER 26, 1999. ACCEPTED INFINALFORM MAy 23, 2000. Reprint requests to: Garth M. Bray, Montreal General Hospital, 1650 Cedar Avenue, Montréal, Québec, Canada H3G 1A4.
} 
autoimmune MG who had a family history of autoimmune MG involving three generations. Relatives of our index case were interviewed and the medical records of three other family members studied for details regarding their diagnosis of MG. Their cases are presented below, followed by a literature review regarding familial autoimmune $\mathrm{MG}$.

\section{Patient 1 (JP)}

This patient's history represents our index case. She initially developed symptoms of diplopia, particularly on gaze to the left, at age 75 years. She had a history of ankylosing spondylitis diagnosed at age 46 years, and type II diabetes mellitus diagnosed at age 71 years. The diplopia recurred with left ptosis at age 80 years. This was followed by the development of mild bulbar symptoms.

She soon developed generalized weakness affecting the arms more than the legs. Her symptoms worsened at the end of the day and after moderate exercise. Subsequent development of severe neck muscle weakness led to hospital admission. A tensilon test was equivocally positive. Repetitive nerve stimulation (RNS) of the left ulnar, facial and spinal accessory nerves did not demonstrate a decrement. Single fibre electromyography (sfEMG) was not performed. ACTscan of the thorax was negative for thymoma. Acetylcholine receptor antibodies were highly positive at $4766 \mathrm{cpm}$ (>2011 cpm). Pyridostigmine was started and she was discharged home.

She was readmitted on two other occasions with progressive weakness and shortness of breath requiring treatment with prednisone, intravenous immunoglobulin, and admission to the intensive care unit. A combination of corticosteroids and azathioprine stabilized her MG, but she remained hospitalized for several more months because of complications.

\section{Patient 2 (CAP)}

This man was the father of our patient. (See Figure.) His medical records stated that he first developed some difficulty with reading at age 75 years. Right ptosis that was more pronounced at the end of the day was described at age 77 years. He had a previous diagnosis of pernicious anemia at age 53 years.

His medical records document right ptosis, as well as possible narrowing of the palpebral fissure on the right. Minimal fasciculations around the orbit of the right eye were also described, as well as weakness of the muscles of the face and neck on the right. He developed difficulty swallowing, then slurred speech and increasing fatigue. A positive tensilon test was reported, however, electromyography was normal. Repetitive stimulation of the orbicularis oculi, and the thenar muscles before and after exercise did not show a significant decrement. SfEMG was not performed. A chest $\mathrm{x}$-ray showed no evidence of thymus enlargement.

He was initially treated with pyridostigmine and prostigmin. Symptoms worsened after these medications were discontinued because of side effects. Amebonium (an acetycholinesterase inhibitor), then prednisone and adrenocorticotropin hormone were tried, but without significant improvement. Over several months, his dose of Amebonium was increased because of difficulty chewing and swallowing. He returned to hospital with difficulty breathing, difficulty with speech and profound weakness of the facial musculature. He developed a hypoxic crisis, but was successfully stabilized. A gastrostomy was placed for continued difficulty with swallowing, but complications following the procedure ultimately led to cardio-respiratory arrest and death.

\section{Patient 3 (SP)}

This man was the younger brother of the second patient. His medical records stated that at age 61 years he sent his daughter a picture of himself in which she noted drooping of his left eyelid. He had no previous illnesses prior to the diagnosis of MG.

His presentation was described as predominantly bulbar, and symptoms were controlled by pyridostigmine for eight years. However, his illness subsequently worsened until he was unable to swallow despite medication. At this time he was noted to have mild weakness of his upper and lower extremities. He responded to a combination of pyridostigmine and prostigmin. He then underwent a thymectomy, but died on the ninth postoperative day. The pathology report described an atrophic thymus.

\section{Patient 4 (DL)}

This man is a nephew of the patient who was our index case. His medical records describe onset of right ptosis worsening with fatigue at age 45 years. These symptoms progressed to include diplopia and generalized fatigue.

Examination revealed moderate right ptosis, which was slightly fatigable with a positive lid twitch sign. There were no other signs of

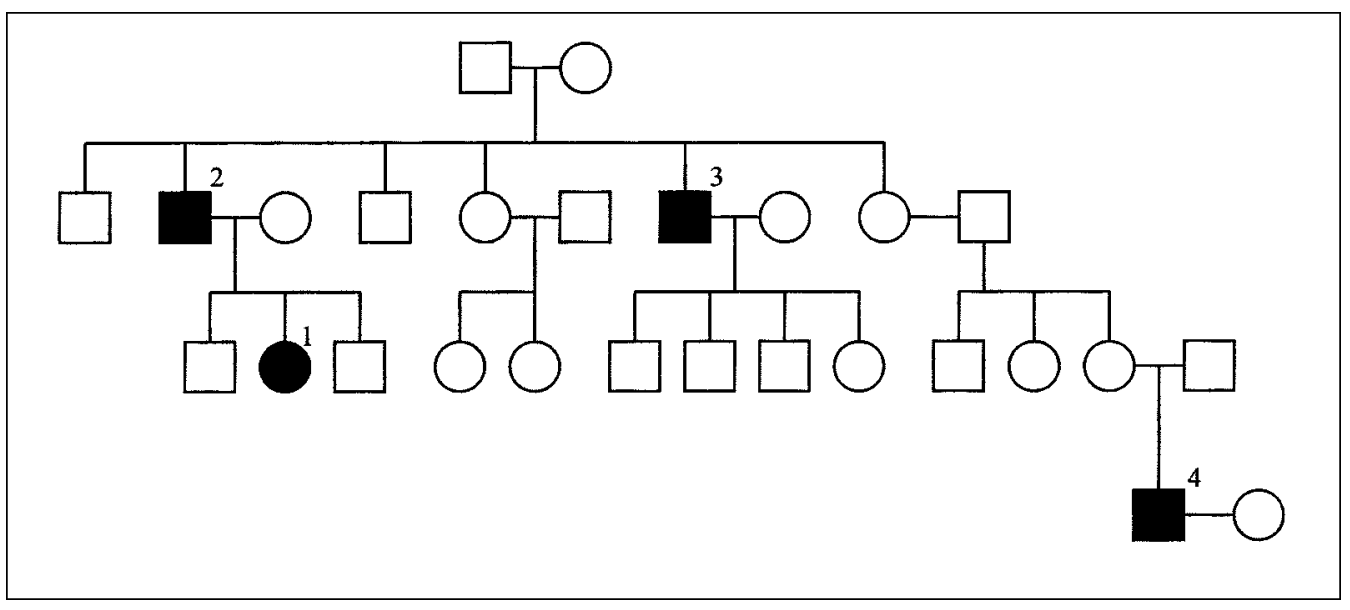

Figure: Pedigree of family with autoimmune myasthenia gravis. Affected individuals are indicated in black. Patient 1 is the index case. 
neurological dysfunction. A CT scan of the thorax was negative for thymoma. Acetylcholine receptor antibodies were markedly elevated $(8.41 \mathrm{nmol} / \mathrm{L})(>0.07 \mathrm{nmol} / \mathrm{L})$

Difficulties with right ptosis persisted. He developed diminished exercise tolerance and excessive fatigue following exertion. Examination two years after onset of ptosis revealed mild weakness of orbicularis oris and the neck flexors, as well as mild fatigability of the proximal limb muscles. The treating neurologist has not performed an EMG, but symptoms are currently well-controlled with pyridostigmine.

\section{Discussion}

We report autoimmune MG in four members of a Canadian family, involving three generations. In Patient 2, it should be noted that the differential diagnosis would include ALS but the ptosis and response to acetylcholinesterase medications makes this unlikely. In patients 1 and 4 the assays performed for AChR antibodies were performed in different laboratories, by different techniques and thus the units reported are different.

Another Canadian family, in which a brother and sister were both affected, has also been described. ${ }^{10}$ Familial autoimmune MG was first reported by Oppenheim in $1900 .{ }^{11}$ However, the distinction between congenital MG arising from hereditary defects expressed at the neuromuscular junction and autoimmune-mediated MG was not always evident in early reports of familial MG. ${ }^{6,8}$

Namba et $\mathrm{al}^{6}$ described a series of 702 myasthenic patients, 27 with a positive family history of $\mathrm{MG}$, representing a familial occurrence of $3.8 \%$. Combining previous reports in the literature, the familial incidence was $3.4 \%$. Cases of congenital MG were subtracted to arrive at a final incidence of $2.7 \%$. A more recent series divided the patients into those with onset of the disease above and below nine years of age. ${ }^{5}$ Familial incidence of MG was $4.5 \%(5 / 112)$ in the younger group but only $0.8 \%(2 / 239)$ in the older group.

Familial autoimmune $\mathrm{MG}$ has been reported in siblings $(58 \%)$, parents $(15 \%)$, cousins $(13 \%)$, second cousins $(4 \%)$, and even more distant relatives $(10 \%) .{ }^{6}$ There are few reports of autoimmune $\mathrm{MG}$ involving more than one generation. ${ }^{6-8}$ Honeybourne $^{7}$ reported three cases of MG in a woman, her niece and one of her granddaughters.

A genetic role for the etiology of autoimmune $\mathrm{MG}$ is suggested by reports of positive family histories. Furthermore, there is an increased tendency for the development of other autoimmune diseases in myasthenics and their family members, specifically thyroid disease, insulin-dependent diabetes mellitus, rheumatoid arthritis, and pernicious anemia. ${ }^{3}$ Kerzin-Storrar et $\mathrm{al}^{4}$ studied 44 patients with MG and noted that $30 \%$ of them had a positive family history of autoimmune disease.

Abnormalities of neuromuscular transmission have been demonstrated in asymptomatic family members of myasthenic patients. Hokkanen et $\mathrm{al}^{12}$ examined 10 healthy controls, 23 myasthenic patients and 29 of their asymptomatic relatives. Abnormalities such as jitter and/or blocking were demonstrated in 10 of the 29 relatives. Lefvert et $\mathrm{al}^{13}$ and Pirskanen et al ${ }^{14}$ also found abnormal sfEMG in 33-45\% of unaffected relatives.

Anti-AChR antibodies have been identified in asymptomatic family members of myasthenic patients. ${ }^{15}$ A 45 -year-old woman with MG and two of her siblings were tested for anti-AChR antibodies. She was found to have significantly elevated titres of
anti-AChR antibodies. Her fraternal twin had intermittent diplopia following an auto accident at age 23 years and developed ptosis of the right eyelid when fatigued. He did not have a decremental response to RNS, but did have elevated antiAChR antibody titres. A sister who was entirely asymptomatic also had elevated titres. Lefvert et $\mathrm{al}^{13}$ found low but significant titres of anti-AChR antibodies in 54\% of unaffected relatives.

Murphy and Murphy ${ }^{2}$ described a set of monozygotic twins each with MG and positive anti-AChR antibodies. Their review of the literature identified 25 reported sets of twins in which at least one member was affected by MG. Both members were affected in five of 14 monozygotic sets. Only a single member of each set was affected in five dizygotic sets, and in six sets of twins of undetermined genetic relationship. Onset of the illness differed by no more than three years between two affected twins in a set, and they also shared a similar distribution of weakness. ${ }^{2}$

However, the genetics of familial autoimmune MG remain unclear. Evoli et $\mathrm{al}^{16}$ studied four Italian families. Three families each had two individuals with MG and a fourth family had a single individual with $\mathrm{MG}$ as well as three other individuals with related (autoimmune) conditions. HLA-typing was performed on all patients. In these families there was no single clinical form of MG, nor was there linkage to a single HLAhaplotype.

Seybold et $\mathrm{al}^{15}$ also tried to establish an association with HLA-type. There was an increased incidence of HLA-B8 in female patients with onset before age 30 years. However, HLAtyping of 245 first- and second-degree relatives of MG patients did not establish a higher incidence of autoimmune, allergic, or endocrine disorders in HLA-B8 positive patients than in HLAB8 negative patients. A subsequent study performing haplotyping of 44 patients with MG and their families also had negative results. ${ }^{4}$ Bergoffen et $\mathrm{al}^{9}$ described a sibship of consanguineous parents in which $\mathrm{MG}$ affected five of ten siblings. HLA haplotype characterization and DNA analysis excluded MHC, the beta subunit of the AChR, and $\mathrm{T}$ cell receptor alpha and beta subunits as candidate genes for the disorder in that family. Other haplotypes, including A1, DR3 and Dw3, have been associated with MG but the strength of all these associations varies with patient subgroup (age, sex, ethnic group). Overall, the association is weak. ${ }^{17}$

The literature suggests that genetic factors play an etiologic role in autoimmune MG, perhaps by determining susceptibility to disease. In experimental allergic MG the susceptibility of mouse strains to disease depends on $\mathrm{H} 2$ haplotypes. ${ }^{17}$ Given the high frequency of other autoimmune diseases in affected MG kindreds, there may be a general susceptibility to autoimmune disease rather than specific susceptibility to $\mathrm{MG}$, possibly partly determined by haplotype. The aforementioned higher concordance rates in monozygotic than dizygotic twins who are HLA-identical in $25 \%$ cases indirectly suggests involvement of non-HLA genes in the pathogenesis of disease. ${ }^{2,17}$ Our kindred provides additional support for such hypotheses. We have described the unusual presentation of four individuals in three successive generations with autoimmune MG. Two of these individuals also had other autoimmune diseases. Single gene inheritance could not be easily used to explain the occurrence of disease in our family; a combination of genes may be involved. Further study of familial cases such as this may help to clarify the contribution of genetic factors to the development of this disease. 


\section{ACKNOWLEDGEMENTS}

The authors thank the medical record departments of the Montreal Neurological Hospital, the Ottawa Civic Hospital, and Dr. K. Stoltz for supplying the necessary medical information regarding the family members of our patient. Thanks are also extended to DP of Montreal, who provided the necessary genealogical data for the patient's family.

\section{REFERENCES}

1. Vincent A, Newland C, Croxen R, Beeson D. Genes at the junction - candidates for congenital myasthenic syndromes. TINS 1997;20:15-22.

2. Murphy J, Murphy SF. Myasthenia gravis in identical twins. Neurology 1986;36:78-80.

3. Christensen PB, Jensen TS, Tsiropoulos I, et al. Associated autoimmune diseases in myasthenia gravis. A population-based study. Acta Neurol Scand 1995;91:192-195.

4. Kerzin-Storrar L, Metcalfe RA, Dyer PA, et al. Genetic factors in myasthenia gravis: a family study. Neurology 1988;38:38-42.

5. Zhi-qiang C. Familial myasthenia gravis. Report of 7 cases in 3 families. Chin Med J 1986;99:749-750.

6. Namba T, Brunner N, Brown SB, Muguruma M, Grob D. Familial myasthenia gravis. Report of 27 patients in 12 families and review of 164 patients in 73 families. Arch Neurol 1971;25:61-72.

7. Honeybourne D, Dyer PA, Mohr PD. Familial myasthenia gravis. J Neurol Neurosurg Psychiatry 1982;45:854-856.
8. Pirskanen R. Genetic aspects in myasthenia gravis. Acta Neurol Scand 1977;56:365-388.

9. Bergoffen J, Zmijewski CM, Fischbeck KH. Familial autoimmune myasthenia gravis. Neurology 1994;44:551-554.

10. Celesia G. Myasthenia gravis in two siblings. Arch Neurol 1965;12: 206-210.

11. Oppenheim H. Diseases of nervous system, 2nd ed. Mayer EE, trans. Philadelphia: J.B. Lippincott 1900:650.

12. Hokkanen E, Emeryk-Szajewska B, Rowinska-Marcinska K. Evaluation of the jitter phenomenon in myasthenic patients and their relatives. J Neurol 1978;219:73-82.

13. Lefvert AK, Pirskanen R, Svanborg E. Anti-idiotypic antibodies, acetylcholine receptor antibodies and disturbed neuromuscular function in healthy relatives to patients with myasthenia gravis. $\mathbf{J}$ Neuroimmunol 1985;9:41-53.

14. Pirskanen R, Bergstrom K, Hammarstrom L, et al. Neuromuscular safety margin: genetical, immunological and electrophysiological determinants in relatives of myasthenic patients: a preliminary report. Ann NYAcad Sci 1981;377:606-613.

15. Seybold ME, Lindstrom JM. Antiacetylcholine receptor antibody and its relationship to HLA type in asymptomatic siblings of a patient with myasthenia gravis. Neurology 1981;31:778-780.

16. Evoli A, Batocchi AP, Zelano G, et al. Familial autoimmune myasthenia gravis: report of four families. J Neurol Neurosurg Psychiatry 1995;58:729-731.

17. Tournier-Lasserve E, Bach J-F. The immunogenetics of myasthenia gravis, multiple sclerosis and their animal models. J Neuroimmunol 1993;47:103-114. 